\title{
Análise de processos subjetivos na relação de cuidado entre familiares ${ }^{1}$
}

\author{
Analysis of subjective processes in the care relationship between family
}

Análisis de los procesos subjetivos en la relación del cuidado en la família

\author{
Bruna de Sousa Cavalcanti ${ }^{2}$ \\ Valéria Deusdará Mori ${ }^{3}$
}

Recibido: 09.06.2016 - Arbitrado: 18.10.201 - Aprobado: 25.01.2017

\begin{abstract}
Resumo
A relação de cuidado é carregada de trocas afetivas e está associada à promoção de qualidade de vida daquele que é cuidado, porém um grande questionamento é onde fica o cuidado para com o cuidador. A proposta abordada nesta pesquisa é analisar produções subjetivas da pessoa que se dedica a ser um cuidador familiar, ou seja, aquele que sem instrução ou estudo sobre a área, desempenha o papel de cuidador. Diante disso, o referencial teórico utilizado é da Teoria da Subjetividade e a metodologia é de caráter construtivo-interpretativo sustentada pela Epistemologia Qualitativa de González Rey. Por fim, após a elaboração de estudo de caso, foi possível construir aspectos como a produção subjetiva do cuidador em relação a seus familiares e em relação aquele que recebe o cuidado, assim como a falta de tempo que o cuidador dispõe para si, e como isso pode trazer consequências para seu modo de vida.
\end{abstract}

Palavras-Chave: cuidadores, cuidar, relação, familiares, subjetividade.

\begin{abstract}
The care relationship is loaded with emotional exchanges and is associated with promoting quality of life of one who is careful. The big question is: Where is the care for the caregiver? The majority proposal in this research is to analyze subjective productions of the person who devotes himself to be a family caregiver, which don't have any instruction or study in the area. The theoretical framework is the Theory of Subjectivity and the methodology is constructive interpretative character supported by Qualitative Epistemology of González Rey. Finally, after the preparation of case study, it was possible to construct aspects like subjective production
\end{abstract}

\footnotetext{
${ }^{1}$ Análise de processos subjetivos na relação de cuidado entre familiares, Centro Universitário de Brasília UniCeub, 2015.

${ }^{2}$ Psicóloga, formada pelo Centro Universitário de Brasília - UniCeub. Brasília, Brasil. bruna.sousacavalcanti@gmail.com

3 Psicóloga, Doutora pela Universidad San Carlos de Guatemala (2009) e mestrado em Psicologia pela Universidade de Brasília (1998). Professora do Centro Universitário de Brasília. Brasília, Brasil. morivaleria@gmail.com
}

Citación del artículo: Cavalcanti, B., Mori, V. (2017). Análise de processos subjetivos na relação de cuidado entre familiares. Revista Katharsis, N. 23, enero-junio 2017, pp.60-69, Disponible en http://revistas.iue.edu.co/index.php/katharsis/index 
caregiver in relation to their families and for the one who receives the care, and the lack of time that the caregiver has for himself, and how this may have consequences for their way of life.

Keywords: caregivers, care, relationship, family, subjectivity.

\section{Resumen}

La relación de cuidado está llena de intercambios emocionales y está vinculada a la promoción de la calidad de vida de la persona cuidada, pero surgue el cuestionamiento sobre el cuidado del mismo cuidador. La propuesta abordada en esta investigación esta orientada a analizar las producciones subjetivas de la persona que se dedica a ser un cuidador familiar, es decir, aquel que sin instrucción o estudio en el área, desempeña el papel de cuidado. El marco teórico utilizado es la teoría de la subjetividad y la metodología es de carácter constructivo interpretativo, apoyado por la epistemología cualitativa de González Rey. Finalmente, después de la preparación de un estudio de caso, fue posible construir algunas categorias corespondientes a la producción subjetiva del cuidador respecto a su precepcion sobre los miembros de su familia y la persona cuidada, así como en relacion a la poca dedicacion al próprio cuidado y cómo esto podría traer consecuencias para su forma de vida.

Palabras clave: Los médicos, Cuidado, Relaciones, Familia, subjetividad.

\section{Introdução}

A relação de cuidado está associada a sobrevivência da espécie humana. Se trata de uma prática antiga, histórica e cultural, e pode ser entendido como uma ação para promover a qualidade de vida daquele que é cuidado. Há grande investimento afetivo e emocional, abordando o cuidado entre adultos, o cuidador também entrará em contato com as dores, sofrimentos e frustrações do outro (Campos, 2005).

$\mathrm{O}$ ato de cuidar envolve um processo de trocas na relação e de responsabilidade, implica ter intimidade com o outro, pois coloca o cuidador em contato com o modo de ser e de viver do outro, e este precisa reconhecer as necessidades do outro, estando sensível ao outro. Dessa forma o cuidado pode se tornar uma atividade cansativa e desgastante. Em decorrência desse envolvimento afetivo e emocional é importante que o cuidador procure cuidar de si e, consequentemente, o cuidado com o outro será de melhor qualidade (Costa \& Silva, 2013).

O cuidado está presente na história de vida de uma pessoa desde o momento de seu nascimento. Temos em nossa infância exemplos e vivência de ser cuidado por alguém, contribuindo para a caracterização do papel do cuidador. Compreendemos esse papel de formas diferentes, visto que cada um entende o cuidar de uma forma. Isso ocorre pela configuração histórica e cultural que a vivência subjetiva do cuidado adquire.

Assim, conceitualmente podemos entender a subjetividade como um sistema complexo, constituído por pessoas, o meio social em que vivem e as relações que estabelecem. Dessa forma, compreenderemos melhor no trecho abaixo de González Rey (2010, p.118):

Citación del artículo: Cavalcanti, B., Mori, V. (2017). Análise de processos subjetivos na relação de cuidado entre familiares. Revista Katharsis, N. 23, enero-junio 2017, pp.60-69, Disponible en http://revistas.iue.edu.co/index.php/katharsis/index 
A subjetividade é um sistema gerado na vida social como produção de caminhos simbólico-emocionais nas histórias das pessoas e das diferentes instâncias que se tecem de forma viva e cambiante na definição social.

Compreende-se que a subjetividade não é somente um processo individual e intrapsíquico, mas sim parte da organização da história de vida das pessoas e dos espaços sociais (Mori \& González Rey, 2011). Nesse sentido, podemos entender isso melhor observando a compreensão sobre o que é cuidar. O cuidado se configura individualmente e socialmente, pois não apenas as experiências individuais se organizam nesse processo, mas também os processos sociais e culturais constituem a forma como esse processo toma forma.

No ato de cuidar há muitas questões emocionais envolvidas e desenvolvidas no decorrer desse processo, pois há a vivência de experiências, que estarão carregadas de sentidos subjetivos. E isso pode ser observado como uma forma de se relacionar, em que há trocas afetivas e reciprocidade entre o cuidador e o ser cuidado, e cada um produzirá sentidos diferentes para a situação vivenciada (Campos, 2005).

Em relação à categoria de sentido subjetivo, González Rey (2010) define-o como sendo uma unidade processual do simbólico e do emocional, que surgem em toda experiência humana. O sentido é carregado pela vasta versatilidade e diversas formas de expressão a nível psíquico das experiências histórico-sociais do sujeito. O sentido expressa a singularidade da realidade vivida, em unidades simbólico-emocionais que através da história do sujeito e do contexto social, se organizam na configuração subjetiva da experiência.

A prática do cuidado é marcada por aspectos da subjetividade social relacionados ao papel feminino e os discursos de gênero. A associação de cuidado com a figura feminina é uma produção cultural e social. A perspectiva da mulher como responsável pela maternidade, pelo cuidado dos filhos e da família ainda está muito marcada na subjetividade social brasileira. Atualmente ainda encontramos mulheres que foram ensinadas que o cuidar do outro é uma qualidade feminina desejável (Paiva Moraes et al, 2009). Em nossa sociedade e nas histórias de vida das participantes dessa pesquisa, os papéis de cuidado são marcados por mulheres, o que evidencia alguns aspectos mencionados anteriormente.

A subjetividade social se define pela constituição de elementos de sentido subjetivo, produções de diferentes áreas da vida social de cada pessoa. Ela se caracteriza por processos que articulam elementos de sentido, entre diferentes espaços da vida social da pessoa. A categoria subjetividade social rompe com a ideia de que a subjetividade é exclusivamente um fenômeno individual, pois quando uma vivência atual ganha sentido e significado dentro da organização subjetiva da história de vida do indivíduo, essa significação pode ser tanto individual quanto social (González Rey, 2005).

Logo é possível identificar aspectos configurados na subjetividade social que se organizam na forma como as pessoas vivem o cuidado com o outro, pois, diferentes processos simbólicos alimentam a forma como nos posicionamos nos processos diversos da vida. Isto posto, a relação entre as profissões de cuidado e a figura feminina se mostra bem articulada e estreita, definindo as configurações subjetivas complexas na organização social dessas profissões. E é nos espaços sociais construídos pela história e pela cultura, em que os

Citación del artículo: Cavalcanti, B., Mori, V. (2017). Análise de processos subjetivos na relação de cuidado entre familiares. Revista Katharsis, N. 23, enero-junio 2017, pp.60-69, Disponible en http://revistas.iue.edu.co/index.php/katharsis/index 
cuidadores estão inseridos, que as experiências vividas irão constituir a subjetividade social dos diferentes espaços relacionados ao cuidado.

A compreensão diferenciada do cuidado, está associada aos processos de subjetivação do indivíduo, e como diferentes sentidos subjetivos se configuram nesse processo, pois cuidar de algo ou alguém são processos singulares que não se organizam de forma padronizada, pois implicam a pessoa a partir de diferentes sentidos subjetivos mobilizados nessa experiência.

$\mathrm{O}$ ato de cuidar mobiliza emoções, que tem grande importância na produção de sentidos subjetivos da pessoa. Diferentes emoções são constitutivas da experiência do cuidado, González Rey (2005) afirma que, uma experiência ou ação só faz sentido para o sujeito quando é portadora de carga emocional, pois as emoções são mobilizadoras da ação, e essas definem o sujeito nos seus espaços sociais e no cenário de cultura. Dessa forma, o cuidado é uma experiência que mobiliza diferentes sentidos subjetivos, e esses também são simbólicos e também agregam carga na constituição subjetiva da experiência do sujeito.

É na troca e na emersão de emoções e processos simbólicos que o cuidador vai produzir sentidos subjetivos com relação a experiência em que está inserido. A partir dos diferentes sentidos subjetivos, que podemos entender as produções subjetivas e a forma como essas vivências e experiências particulares, afetam e integram o que é o cuidar para o sujeito. Nesse sentido podemos entender que essas emoções mobilizadoras despertam no cuidador laços afetivos que envolve sua relação com seu familiar, o que pode ser um motivador para o desempenho do papel de cuidador (Marques Vilaça et al, 2005).

\section{Método}

A metodologia empregada na presente pesquisa apoia-se nos pressupostos da epistemologia qualitativa proposta por González Rey (2010). Metodologia essa que tem caráter construtivo-interpretativo do conhecimento, visto que a proposta metodológica evidencia a compreensão da pesquisa como processo dialógico que implica o pesquisador e os participantes.

O caráter subjetivo estudado, implica que os sentidos subjetivos não devem ser estudados como expressão direta das influências externas aos participantes, mas pela própria construções do pesquisador. $\mathrm{O}$ participante se envolve em um processo de diálogo durante a pesquisa, e isso contribui para a produção de diferentes sentidos subjetivos que se constituíram na relação com o pesquisador e com a pesquisa (Mori \& González Rey, 2011)

\section{$\underline{\text { Instrumentos }}$}

Dentro do espaço dialógico, entre pesquisador e participante, os instrumentos serão indutores da expressão dos participantes. Eles permitem o desenvolvimento de hipóteses apoiadas em indicadores que o pesquisador desenvolve na pesquisa. Os indicadores se definem pelo conjunto de elementos de sentidos expressos pelo participante, essas expressões se relacionam através de interpretações e construções do pesquisador (González Rey, 2010, 2005b).

Para contribuir com a construção do conhecimento, os instrumentos, utilizados nessa pesquisa, foram as dinâmicas conversacionais e o complemento de frases. Essa pesquisa foi

Citación del artículo: Cavalcanti, B., Mori, V. (2017). Análise de processos subjetivos na relação de cuidado entre familiares. Revista Katharsis, N. 23, enero-junio 2017, pp.60-69, Disponible en http://revistas.iue.edu.co/index.php/katharsis/index 
organizada em um estudo de caso. Ocorreram três encontros com a participante, de acordo com sua disponibilidade cada encontro teve duração de aproximadamente uma hora. O número de encontros se definiu pela necessidade de aprofundar diferentes elementos que se evidenciaram nos espaços de conversação. Esses instrumentos facilitaram o acesso das experiências do sujeito, que por sua vez, é capaz de estimular sentidos subjetivos diferentes durante o diálogo.

\section{$\underline{\text { Participantes }}$}

Este estudo selecionou uma participante que atendiam ao pré-requisito de estar no papel de um cuidador familiar. Se utilizou das redes sociais, Facebook ${ }^{\circledR}$, por meio de uma publicação em um grupo de psicologia, para selecionar pessoas que atendiam ao pré-requisito. A pesquisa se utilizou desse recurso, pois dessa forma não haveria vínculo prévio com o participante, e pela abrangência de pessoas poderia encontrar um cuidador familiar do gênero masculino.

\section{Resultados: Construção da Informação - Aline}

Aline, 33 anos, é estudante, solteira, é cuidadora familiar principal de sua mãe, que se encontra com 67 anos, e necessita de cuidados, pois faz uso abusivo de substâncias psicoativas. O pai de Aline faleceu há aproximadamente três anos, e ela tem três irmãos.

No trecho a seguir Aline comenta sobre sua infância e de sua relação com sua mãe:

Não me lembro de muitas coisas da minha infância, mas lembro da minha relação com ela que era de muita briga, lembro do meu pai trabalhando, ele era militar, policial. Lembro muito da minha tia, irmã da minha mãe, ela cuidava da gente, somos quatro irmãos, ela levava a gente para passear, ela fazia coisas de mãe. Minha mãe sempre foi dona de casa, lembro dela brigando por causa da limpeza da casa, lembro dela nas reuniões de família, ela sempre bebendo. Mas aquela presença de mãe mesmo eu lembro mais da minha tia.

Nesse trecho podemos ver que a tia ocupava o lugar do afeto, e a mãe uma referência carregada de lembranças negativas, Aline apresenta certa contradição quando menciona a ausência de uma figura materna. Mesmo descrevendo a mãe como ausente, ela ainda fazia o papel de cobrar nos estudos, e ela teve sua tia, que foi presente e a qual ela se refere como tento um papel de mãe. Temos como indicador da relação contraditória com a mãe, pois atualmente isso gera diferente processos que se apresentam no trecho a seguir:

Então eu fiquei cuidando dela, com a condição de que eu poderia cursar minha faculdade. Minha única vontade era de fazer a faculdade, porque eu não sei o que vai ser daqui para frente, eu posso morrer e fica minha mãe, mas eu posso não morrer e minha mãe pode chegar a falecer eu tenho que ter uma profissão, porque eu larguei minha vida para ficar cuidando dela.

Aline parece ter consciência das concessões que ela fez em detrimento a sua mãe.

Nesse trecho, evidencia-se o valor do estudo para ela, marcado pela dificuldade em poder realizar-se nesse sentido. Os processos subjetivos que se organizam em relação à mãe, como

Citación del artículo: Cavalcanti, B., Mori, V. (2017). Análise de processos subjetivos na relação de cuidado entre familiares. Revista Katharsis, N. 23, enero-junio 2017, pp.60-69, Disponible en http://revistas.iue.edu.co/index.php/katharsis/index 
assinalado anteriormente, se expressam contraditoriamente. Ao mesmo tempo que precisa cuidar da mãe, abre mão de coisas importantes para sua vida. Mas, a responsabilidade que assume implica também pensar no futuro e na própria vida para além do cuidado com a mãe, o que indica que tenta não se subordinar a esse momento e faz planos para o futuro.

A seguir, temos indicador sobre a relação de Aline com a mãe que se integra a outros indicadores que apareceram anteriormente e nos possibilitam falar de diferentes sentidos subjetivos que se configuram nesse processo:

Meu antigo relacionamento era um pouco complicado, porque ele queria fazer algumas coisas que não dava para mim. Vamos viajar, vamos fazer isso, vamos fazer aquilo, e para mim não dava, eu tinha sempre a preocupação da minha mãe. Às vezes eu saia para casa dele para namorar, mas eu tinha que levar a minha mãe, para que ela não ficasse sozinha. Porque se ela ficasse sozinha ela ia sair para beber e meu pai ia chegar a noite e ia ter briga, e ele agredia ela. Eu queria mais que ele fosse para dentro da minha casa. Na época eu não soube conciliar muito bem as coisas, eu acho que ele também não me ajudou e não foi tão compreensivo nessa situação.

O cuidado se organiza em processos de sentido que se expressam na incapacidade de gerar espaços próprios de relacionamentos, Aline está subordinada ao cuidado com a mãe. Não compreende que ela estava colocando a mãe dentro do relacionamento, ela não se posiciona de forma ativa em relação a suas próprias questões, pois ela só dá visibilidade para as questões da mãe. As ações de Aline dentro do contexto de um relacionamento amoroso causaram reações em seu parceiro da época. E ela não entende isso como sendo algo que ela provocou, mas sim uma falta de boa vontade do outro.

Pensando que Aline é um ser dialético e complexo, podemos discutir sobre a construção do sujeito, que é constituído pelo social e individual. Aline é uma cuidadora, é sujeito que passa a ter o social, relacionamentos e trocas. Mas também vê o ato de cuidar como sendo uma constante em sua vida, e podemos identificar isso na forma como ela dedica sua vida a mãe. Assim, Aline sofre influências em sua organização, e na forma como se relaciona com o outro, pois suas ações nos espaços sociais se configuram subjetivamente, e a importância que ela dá para as relações de cuidado que mantém com sua genitora.

Na situação de Aline, podemos identificar a categoria de sentido subjetivo, uma unidade processual do simbólico e do emocional, que surge em toda experiência de relações que ela estabelece.

Dessa forma, o ato de cuidar gera muitas questões emocionais envolvidas e desenvolvidas no decorrer desse processo. Aline se vê em situações que a levam a cada vez mais fortalecer os laços de cuidado, a vivência de experiências com a mãe estará carregada de sentidos subjetivos. E isso pode ser observado como uma relação de mão dupla, em que há trocas afetivas e reciprocidade entre o cuidador e o ser cuidado, e cada a mãe de Aline também produzirá sentidos diferentes para a situação vivenciada

O posicionamento dependente de Aline, em relação a sua mãe, parece ser uma expressão de sentidos subjetivos de seu padrão de relacionamento com os outros. O relacionamento com

Citación del artículo: Cavalcanti, B., Mori, V. (2017). Análise de processos subjetivos na relação de cuidado entre familiares. Revista Katharsis, N. 23, enero-junio 2017, pp.60-69, Disponible en http://revistas.iue.edu.co/index.php/katharsis/index 
sua genitora é extremamente carregado de afetos, e isso não lhe permite assumir decisões e formas próprias de se posicionar perante sua vida. Podemos ver isso no trecho a seguir:

Eu queria muito ter me casado e ter construído a minha família, e isso eu não pude fazer.

Aline orientou sua vida para o cuidado com a mãe. Salientamos que esse é um processo muito comum nas relações de cuidado. $\mathrm{O}$ cuidador abre mão de muitos projetos pessoais, e como afirmamos no início do trabalho, percebe-se que o cuidado é responsabilidade das filhas na maioria das situações. A frustração pelo que não foi vivido é pouco valorizada, pois na subjetividade social dominante, cuidar dos pais é um valor importante. E as contradições nesse percurso são invisibilizadas, pois o cuidador tem que ser um abnegado.

\section{Sempre quis: Ser mãe. Porém há dois anos eu descobri que tenho endometriose e que isso causa infertilidade, então além do problema da minha mãe eu teria que fazer tratamento para poder engravidar.}

É interessante que Aline tem o desejo de ter uma família, porém ainda assim, ela não se sente com recursos subjetivos para avançar na sua concretização. Ela não consegue superar o problema e procurar maneiras criativas de conciliar o cuidado da mãe e de realizar seus objetivos de vida.

Os sentidos subjetivos configurados na relação com a mãe nos indicam excesso de cuidado em detrimento do próprio cuidado. Assim como a contradição da relação com a mãe não é mobilizadora de processos subjetivos que possibilitem gerar novas alternativas para viver a vida em outros termos. Nos parece interessante articular essa experiência com a ideia de codependencia. $\mathrm{O}$ que gera uma preocupação permanente em cuidar e se relacionar com o outro, ou seja, sua mãe. Isso leva Aline a fazer coisas que ela não gosta, e ela irá procurar agradar principalmente a mãe em vez de a si mesmo (Paiva Moraes et al, 2009). E seguindo esse pensamento, se não houver uma mudança na configuração subjetiva de Aline em relação a mãe, ela continuará nessa relação simbiótica. O que podemos constatar que novamente temos um indicador que ela prefere a mãe do que a si mesmo.

Durante a conversa perguntei a Aline como ela se sente nessa relação com sua mãe:

Eu sinto como se ela fosse minha filha, eu a mãe.

A relação invertida mantida por Aline desde sua adolescência, está naturalizada.

Aline não se posiciona em relação a sua própria vida, ela fez uma escolha no passado que a rege até hoje sua vida, o que nos leva de volta ao modo de vida e ao fator alienante que a naturalização e acomodação gera no sujeito. É interessante que ela não mantém nenhuma atividade orientada para a mudança do seu modo de vida, utilizando o argumento que a escolha de cuidar da mãe não foi dela, sem entrar em uma reflexão sobre a forma como vive e sobre os reflexos que isso pode ter durante toda a sua vida. Aline se posiciona de forma passiva, e que se expressa na sua incapacidade para produzir alternativas em seu modo de vida, e se torna um empobrecedor para suas relações sociais.

Citación del artículo: Cavalcanti, B., Mori, V. (2017). Análise de processos subjetivos na relação de cuidado entre familiares. Revista Katharsis, N. 23, enero-junio 2017, pp.60-69, Disponible en http://revistas.iue.edu.co/index.php/katharsis/index 
Aline tem um sentimento de dívida com sua mãe, ela se sente na obrigação de cuidar da mãe, porque um dia essa cuidou dela. Em seu complemento de frases ela expressa:

Minha mãe: responsável pela minha existência. Porque foi ela que me gerou.

Não posso: abandonar minha mãe, ou não está por perto e deixa-la se sentindo desamparada.

Na relação de cuidado, é comum que o codependente negue seus desejos, se anulando em detrimento do outro. Também já podemos observar o sentimento de culpa desenvolvido por Aline na condição de codependente, isso pode levar a falta de imposição de limites, por parte do cuidador. Ela acaba por perder seu amor próprio e a sua capacidade de se afirmar e cuidar de si mesmo. Mesmo Aline amando a mãe, e reconhecendo a genitora, essa se encontra em um conflito, que pode ser inconsciente, e se sente culpada pelos sentimentos negativos ou por causar desconforto a sua mãe. Aline busca muito o conforto e o bem-estar de sua mãe, essa condição acaba por favorecer a diminuição da auto estima, do autocuidado, e do interesse sobre si própria. A auto estima do codependente, muitas vezes é regulada pelo outro, pela capacidade de agradar o outro ou não (Paiva Moraes et al, 2009).

Além disso podemos detectar aspectos da subjetividade social de Aline que a fazem perpetuar seu papel como cuidadora. A vivência dela com a genitora é carregada de sentido e significado dentro da organização subjetiva da história de vida de Aline, e essa significação pode ser tanto individual quanto social, como podemos ver no trecho abaixo:

Foi bem revoltante sabe? Eu não queria fazer aquilo, eu queria que todos os irmãos sentassem e dividissem as obrigações, só que todas as vezes que eu tentei fazer isso, as coisas que eu escutava dos meus irmãos, eu não aceitava. A minha irmã mais velha, por exemplo, falava que era a favor de pagar alguém para ficar cuidando da minha mãe. Meu irmão já falava para interna-la em algum lugar. Quando eu penso em internar a minha mãe eu me sinto mal, porque, se hoje eu estou sentada aqui conversando com você, foi porque um dia minha mãe escolheu por mim quando eu nasci, e ela me cuidou com todos os problemas dela. Ela estava lá e ela cuidou de mim. Ela podia ter me abortado, podia ter me dado, podia ter feito um monte de coisas, mas ela cuidou de mim. Então essa é a minha obrigação de filha, futuramente se eu tiver um filho ele me largar e me internar, eu sei que isso foi uma opção dele, ele escolheu assim, não é porque a vida está me devolvendo aquilo que que fizcom a minha mãe, entende? No início foi ruim, hoje eu já tenho mais uma maturidade, eu já olho para essa situação e acho que eu realmente sou a que tem mais paciência, $e$ a que realmente tem uma estrutura psicologia para lidar com essa situação. Acho que eu não ia me sentir bem se eu soubesse que ela estava internada, eu não ia dormir com a minha cabeça tranquila.

Os processos subjetivos envolvidos nas distintas configurações subjetivas atuais da vida de Aline são fontes de sentidos subjetivos, que sustentam a relação de codependencia. O que gera um fortalecimento da configuração subjetiva dos atos e processos cotidianos realizados por Aline, que acabam ganhando força para anular sua capacidade de gerar alternativas frente

Citación del artículo: Cavalcanti, B., Mori, V. (2017). Análise de processos subjetivos na relação de cuidado entre familiares. Revista Katharsis, N. 23, enero-junio 2017, pp.60-69, Disponible en http://revistas.iue.edu.co/index.php/katharsis/index 
seus estados afetivos dominantes. Podemos somar a isso a trama afetiva atual da vida de Aline que faz parte dos estados emocionais perante os quais ela não consegue se posicionar e definir opções.

Aline, por ter assumido papel de cuidado desde a adolescência, já entende o ser cuidadora como parte de si. O contexto familiar de Aline proporcionou a ela experiências que agora compõe sua subjetividade individual e a forma como ela lida com sua genitora. Ela ainda se vê presa a relação de cuidado com a mãe, e isso pode estar relacionada a situação de codependência que ela desenvolveu em relação sua genitora. Dessa forma é mais evidente vivências de culpa e dever na situação se cuidado entre Aline e sua mãe, pois os sentidos subjetivos conseguintes dessa relação, não permitem que Aline procure recursos para tomar decisões sobre sua própria vida.

\section{Considerações Finais}

O papel de cuidador é uma experiência intensa, que assume sentido subjetivo a partir de seus efeitos na vida do cuidador, e são esses efeitos produzidos no processo de viver a experiência, que se organiza as configurações subjetivas do processo de cuidado. Ou seja, as diferentes configurações subjetivas organizadas no processo de cuidar e também no processo saúde-doença carregam a história de vida do cuidador e sua organização singular, o que nos remete ao caráter singular das configurações subjetivas.

As configurações subjetivas do ato de cuidar ocorrem de maneira particular e estão associadas a esferas da vida individual, social e cultural de cada cuidador. A experiência de cuidar pode ser percebida e refletida quando ganha sentidos subjetivos dentro da configuração subjetiva que emerge das vivencias como cuidador que uma pessoa teve.

Por meio da análise dos processos subjetivos que envolvem o cuidar do outro, foi possível identificar a falta do cuidado para si mesmo, e como isso pode ter consequências na vida do cuidador familiar.

Dessa forma, podemos considerar que as configurações subjetivas apresentadas no processo de cuidar revelam aspectos da subjetividade social que se configuram nos cuidadores, mas que aparecem por meio de sentidos subjetivos distintos em cada configuração da subjetividade individual do cuidador.

Um aspecto da subjetividade social relevante que podemos destacar nesse estudo, é a posição da mulher como sendo cuidadora principal, e além disso, assumindo os cuidados domésticos. Isso deve ser considerado, pois temos como realidade social, a presença preponderante de mulheres no papel de cuidado. Dessa forma, podemos entender o papel da mulher cuidadora, como sendo uma representação social, ou seja, uma construção feita pela sociedade. A mulher está ligada ao cuidado pela maternidade, e esse conhecimento social se apropria das produções de cuidado desenvolvido em outras esferas da vida de uma pessoa. Contudo, a representação social da mulher como cuidadora, conserva o caráter construtivo de configurações subjetivas nos cuidadores em seus espaços sociais.

Assim, assumir todos esses cuidados deve ser desgastante, seja para cuidadores do gênero feminino, ou não, os sentidos e significados organizados na subjetividade social tem

Citación del artículo: Cavalcanti, B., Mori, V. (2017). Análise de processos subjetivos na relação de cuidado entre familiares. Revista Katharsis, N. 23, enero-junio 2017, pp.60-69, Disponible en http://revistas.iue.edu.co/index.php/katharsis/index 
desenvolvimentos importantes nos processos de subjetividade da pessoa, e como essa enfrenta os cuidados do outro e de si próprio.

Dessa forma, podemos refletir sobre a promoção de saúde na população de cuidadores familiares, principalmente a promoção de saúde mental. Dado que os cuidadores familiares, como foi visto nessa pesquisa, dão preferência ao outro do que a si mesmo.

Logo, podemos concluir que, cuidar de si para poder cuidar do outro é uma prerrogativa importante para se trabalhar com cuidadores familiares. E que o psicólogo tem papel fundamental em refletir sobre as diferentes organizações das experiências humanas, a fim de construir formas teóricas e práticas para promover a promoção de saúde dos cuidadores familiares. E dessa forma compreender a articulação de processos individuais e sociais que geram sentido e significado e constituem as configurações do sujeito.

\section{Referências}

Costa, I., Silva, E. (2013). Dores dos “Cuida-dores” em saúde mental. Brasília: Universidade de Brasília.

Campos, E. (2005). Quem Cuida do Cuidador: Uma proposta para os profissionais de saúde. Rio de Janeiro: Vozes.

González Rey, F. (2005). Sujeito e Subjetividade: Uma aproximação histórico-cultural. São Paulo: Pioneira Thomson Learning.

González Rey, F. (2005b). Pesquisa Qualitativa em Psicologia: caminhos e desafios. São Paulo: Pioneira Thomson Learning.

González Rey, F. (2010). Pesquisa Qualitativa e subjetividade: Os processos de construção da informação. São Paulo: Cengage Learning.

Paiva Moraes, L., Batista Braga, V., Alves e Souza, A., Batista Oriá, M. (2009). Expressão da Codependência em familiares de dependentes químicos. Revista Min. Enfermagem, 13(1), 34-42, Diponível em www.reme.org.br/exportar-pdf/160/v13n1a06.pdf

Mori, V., González Rey, F. (2011). Reflexões sobre o social e o individual na experiência do câncer. Revista Psicologia \& Sociedade, 23(n. spe), 99-108, Dsiponível em www.ufrgs.br/seerpsicsoc/ojs/include/getdoc.php?id...pdf

Marques Vilaça, C., Barreiros, D., Galli, F., Torquetti Borçari, I., Fernandes de Andrade, L., Goulart, M., Conceição, C., Mohallem Carneiro, M. (2005). O autocuidado de cuidadores informais em domicilio- percepção de acadêmicos de enfermagem. Revista Eletrônica de Enfermagem,07(02), 221-226, Diponível em https://www.fen.ufg.br/fen_revista/revista7_2/pdf/RELATO_02.pdf

Citación del artículo: Cavalcanti, B., Mori, V. (2017). Análise de processos subjetivos na relação de cuidado entre familiares. Revista Katharsis, N. 23, enero-junio 2017, pp.60-69, Disponible en http://revistas.iue.edu.co/index.php/katharsis/index 